\title{
Vertical and Horizontal Mobility in the Domestic Labor Market
}

\author{
Fedorova E.P. \\ Astrakhan State University, 20A Tatischev Str.,Astrakhan, \\ Russia \\ e-mail: lenafedorova@mail.ru
}

\author{
Glinchevskiy E.I. \\ Astrakhan State University, 20A Tatischev Str.,Astrakhan, \\ Russia \\ e-mail: ned81@yandex.ru
}

\author{
Utaralieva R.T. \\ Astrakhan State University, 20A Tatischev Str.,Astrakhan, \\ Russia \\ e-mail: utaralieva1995@gmail.com
}

\begin{abstract}
Labor mobility influences flexibility of the labor market, as well as the adaptation potential of economy. Companies with a high rate of internal mobility of their staff have additional advantages.

The paper analyzes the scale and dynamics of internal mobility at the Russian labor market in accordance with obtained RLMSHSE data, which is a Russian longitudinal representative microeconomic survey, over 2006-2015. Over this period, there was a decrease in upward and downward mobility, as well as in the overall share of the internally mobile. The compiled transition matrix to reveal influence exerted by employees' mobility the previous year upon their mobility the next year has proved that upward and downward mobility are factors that reduce probability of employees' change of work. Based on a multinomial logistic regression that we have compiled, as well as on our simulation of conditional probabilities with regard to regression coefficients, we have identified the factors that influence various types of workforce mobility. The authors conclude that internal mobility determines the labor market dynamics and contributes to its flexibility.
\end{abstract}

Keyword-internal mobility; vertical mobility; horizontal mobility; regression analysis; panel data.

\section{INTRODUCTION}

Under the current economic conditions, the internal labor market is of special value, since it unites all the subjects of labor relations; thus, it is essential to consider the mechanism of its operation at the microlevel. Internal mobility is a tool to develop personnel; it provides one's professional and personal growth and contributes to the development of the very organization by forming top-level human resources. It makes it possible to enhance competitiveness of both an individual employee in particular and the entire organization in general.

Internal mobility manifests itself as an employee's movement up or down the hierarchical system of managerial positions. This type of mobility refers to vertical movement, as it may be upward or downward. Besides, internal mobility implies moving within a department or between the departments of the same organization - this is horizontal mobility. Horizontal mobility may be due to various factors: corporate needs, staff's dissatisfaction with particular aspects of their labor activities, such as labor management, everyday working conditions, the psychological climate in their teams, etc.

Numerous empiric research papers analyze workforce mobility in the internal labor market. Foreign research relates to countries of North America, Europe, and Eastern Asia. The United States, Sweden, and Germany are the countries where such research was conducted in the most comprehensive and detailed way. There may be different scopes of mobility in different countries. Comparison of internal mobility rates is complicated, since countries have institutional differences, their labor markets are regulated differently, and they may apply different research methods and techniques [1, p. 207].

\section{BRIEF LITERATURE REVIEW}

The research papers concerning internal mobility focus mainly on analyzing upward mobility and its influence upon salaries. A. Frederiksen, T. Halliday, and A. K. Koch conclude that a considerable short-term growth of salaries is due to external mobility at the non-managerial level, whereas a longterm growth is due to one's promotion to a higher position in the same or a different organization, or due to external mobility at the managerial level [2, p. 337]. According to M. Javdani and A. McGee, growth of women's salaries is $3 \%$ lower than that of men's salaries after their promotion, provided all the other conditions are equal. They also revealed a "family difference" in return on salaries that is due to one's promotion: single and childfree women have the same return on salary as men, whereas women who have a family face a lower return on salary [3, p. 22].

At the same time, few papers concern internal horizontal mobility. In particular, T. J. Dohmen, B. Kriechel, and G. A. Pfann analyzed the data of a Dutch aviation plant and concluded that horizontal mobility influences promotion prospects and salary growth; it is also a particular career stage [4, p. 223]. M. Bidwell, who researched the data of a US financial institution over 2003-2009, revealed that internal vertical mobility made up $55 \%$ over that period, external mobility - $32 \%$, in- 
ternal horizontal mobility $-10 \%$, and simultaneous vertical and horizontal mobility $-3 \%$ [5, p. 384].

Besides, many authors identify the gender aspect of internal mobility in their papers. According to H. Cassidy, J. DeVaro, and A. Kauhanen, who researched Finland's private sector over 2002-2012, should all other conditions be equal, probability of promotion for male "white collars" is $26 \%$ higher than for female ones [6, p. 139]. P. Ferreira remarks that higher education influences female mobility more profoundly than male mobility [7, p. 20].

As for the Russian literature, it presents few empiric research papers related to internal mobility. D. V. Nesterova and I. O. Maltseva, who applied personal data of a Russian institution, analyze internal labor mobility and its impact upon changes in employees' salaries [8, c. 44]. Their other paper Gender Segregation in Internal Labor Market: Factors \& Consequences - considers the causes of gender segregation and its impact upon the workforce's labor output [9, c. 254]. As for the research by S. A. Solntsev, which is based on data concerning Russian top managers' mobility, it analyzes the factors that influence the correlations between internal promotion and external appointments to top managerial positions in Russia [10, p. 30].

Among the research papers applying household surveys to analyze internal mobility, one could mention only the paper by V. E. Gimpelson, R. I. Kapelyushnikov, and A. V. Sharunina, who apply RLMS-HSE data over 2006-2013 to research two forms of labor mobility: vertical internal and external mobility. Their paper considers the dynamics and determinants of mobility, correlation between mobility and the human capital, and influence of mobility upon salaries [1, p. 237].

\section{OBJECTIVES}

The purpose of this article is to determine the relationship between vertical and horizontal mobility in the domestic labor market. We must solve the following tasks to achieve this goal: to analyze the structure and dynamics of labor mobility; to assess the scale and intensity of intrafirm moves; identify the factors that have an impact on internal mobility.

\section{STRUCTURE AND DYNAMICS OF LABOR MOBILITY}

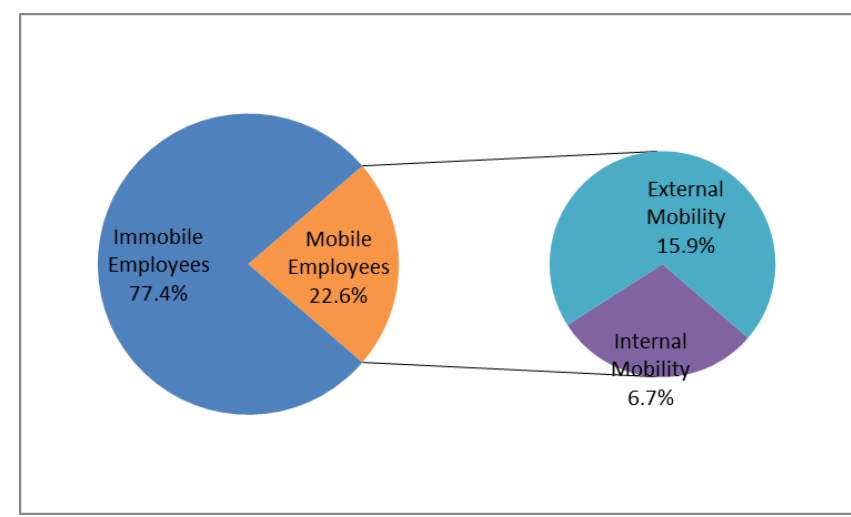

Fig. 1. Structure of Labor Mobility over 2006-2015 (Average Values). Compiled by Authors as per RLMS-HSE Data.
Fig. 1 displays the structure of labor mobility with regard to average values of the RLMS-HSE ${ }^{1}$ data over 2006-2015: approximately one in five employees were mobile within this period $(22.6 \%)$; at that, only three in ten employees were internally mobile; external mobility exceeded internal mobility approximately 2.4 times.

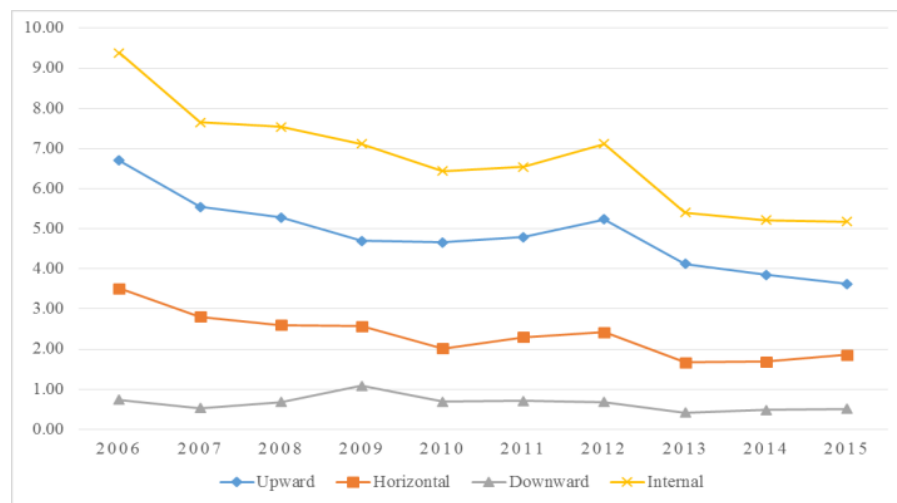

Fig. 2. Dynamics of Internal Mobility, \%Compiled by Authors as per RLMSHSE Data.

Fig. 2 presents dynamics of internal mobility as per RLMSHSE data over 2006-2015. Throughout this period, in average $6.7 \%$ of all the employees were internally mobile. Upward mobility was the most intensive: $4.9 \%$ obtained a higher position; $2.3 \%$ commenced to work in another department; $0.7 \%$ obtained a lower position. At the same time, upward and horizontal mobility decreases, as well as the total share of the internally mobile. There are no sustainable tendencies in downward mobility; its rate did not exceed $1 \%$, except for 2009 (1.1 $\%)$. Upward mobility also decreased that year significantly. These facts reflect the impact exerted by the 2008 crisis; there are also considerable reductions over the 2014 crisis [3]

To determine how an employee's previous-year mobility influences the same employee's next-year mobility, we have compiled a transitions probability matrix. It is represented in Table 1. Given the obtained data, obtainment of a higher position is the most probable for those who were promoted the previous year, as well as for those who demonstrated their upward and/or horizontal mobility the year before. Therefore, upward and horizontal mobility act as career steps. Transition to another department is more probable for those who demonstrated only horizontal mobility or both horizontal and downward mobility the previous year. A lower position is more probable for those who were shifted to a lower career step the year before as well, or for those who both received a lower position the previous year and at the same time commenced to work in another department.

Therefore, each type of mobility has more chances to happen provided the corresponding mobility occurred over the preceding period. One should remark that internal transitions

\footnotetext{
1 Russia Longitudinal Monitoring Survey of Population's Wealth \& Health (RLMS-HSE) conducted by the Higher School of Economics - National Research University jointly with University of North Carolina at Chapel Hill (USA), the Research Center "Demoscope", and the Institute of Sociology of the Russian Academy of Sciences (ISRAS) (web sites of RLMS-HSE research http://www.cpc.unc.edu/projects/rlms and http://www.hse.ru/rlms).
} 
reduce probability to lose a job, except for downward mobility. mence to work in another department. Change of work is most probable for employees who com-

TABLE I. MATRIX OF TRANSITIONS BETWEEN UPWARD, HORIZONTAL, DOWNWARD MOBILITY, AND THEIR COMBINATIONS, IMMOBILITY, EXTERNAL MOBILITY, AND UNEMPLOYMENT, 2006-2015 (AVERAGE VALUES), \%

\begin{tabular}{|c|c|c|c|c|c|c|c|c|c|}
\hline \multirow[b]{2}{*}{ Previous-Year Mobility Status } & \multicolumn{9}{|c|}{ Current-Year Mobility Status } \\
\hline & Up. & H. & Dwn. & Up.+H. & H.+Dwn. & Up.+H.+Dwn. & I. & Ext. & Unem. \\
\hline Upward (Up.) & 16.7 & 1.4 & 1.05 & 2.11 & 0.42 & 0.08 & 67.7 & 10.1 & 0.42 \\
\hline Horizontal (H.) & 7.34 & 7.7 & 0.26 & 1.57 & 0.26 & 0 & 69.2 & 13.5 & 0.13 \\
\hline Downward (Dwn.) & 4.37 & 2.6 & 8.3 & 0.44 & 2.62 & 0 & 68.1 & 12.2 & 1.31 \\
\hline Up.+H. & 13.42 & 4.3 & 0.22 & 7.58 & 0.87 & 0.22 & 60.6 & 12.3 & 0.43 \\
\hline H.+Dwn. & 4.26 & 8.5 & 5.32 & 2.13 & 3.19 & 0 & 68.1 & 8.51 & 0 \\
\hline Up.+H.+Dwn. & 2.56 & 2.5 & 2.56 & 0 & 0 & 0 & 79.5 & 12.8 & 0 \\
\hline Immobility (I.) & 2.72 & 1.0 & 0.39 & 0.45 & 0.15 & 0.08 & 85.4 & 9.03 & 0.71 \\
\hline External (Ext.) & 4.4 & 1.2 & 0.17 & 0.95 & 0.06 & 0.02 & 61.0 & 30.6 & 1.51 \\
\hline Unemployment (Unem.) & 3.63 & 1.3 & 0.19 & 1.25 & 0.04 & 0.08 & 61.4 & 23.0 & 9.03 \\
\hline
\end{tabular}

\section{V.MODEL}

To determine what factors influence internal mobility, a multiple choice model has been composed by applying a multinomial logistic regression. In terms of Mathematics, the multinomial logistic regression is represented as follows [11, p. 333]:

$$
P\left\{y_{t}=j\right\}=\frac{\exp \left\{x_{t}^{\prime} \beta_{j}\right\}}{1+\exp \left\{x_{t}^{I} \beta_{2}\right\}+\cdots+\exp \left\{x_{t}^{I} \beta_{M}\right\}}, j=1,2, \ldots, M
$$

The dependent variable acquires five possible values: 1 vertical mobility; 2 - horizontal mobility; 3 - mixed mobility; 4 - external mobility; 5 - immobility. Upward mobility and downward internal mobility were united owing to minute values of the latter. The independent variables are: gender, age group, education, marital status, settlement type, company size, form of property, profession, sector, subordinates, year of research conducted, federal district.

\section{RESULTS}

With all the other conditions equal, men and women have equal chances for various internal promotion; there are minute differences in coefficients of vertical, horizontal, and mixed mobility. Family status does not influence internal mobility, either. As employees are getting older, all the types of internal mobility decrease; in general, internal mobility decreases from $10 \%$ among individuals aged under 30 to $3 \%$ among individuals aged over 50 . Vertical mobility decreases from $7 \%$ to $2 \%$ for similar groups. Analyzing the descriptive data, a link between education and internal mobility has been revealed. No link has been identified when other variables were considered. V. E. Gimpelson, R. I. Kapelyushnikov, and A. V. Sharunina present the same findings: no link between internal mobility and education is revealed when workplace characteristics are included in the regression; however, this regularity is revealed when those characteristics are disregarded [1, p. 227]. The larger a settlement is, the more probable internal mobility is. There are maximal values related to internal mobility in Moscow and Saint Petersburg.
Therefore, internal mobility determines the dynamics of the internal labor market and acts as a factor that makes it flexible. Internal mobility, together with other factors, contributes to the right balance between workforce supply and demand in the internal labor market. This analysis has proved that should all other conditions be equal, men and women have equal chances for internal career promotion. Marital status does not influence internal mobility. As employees are getting older, all the types of their internal mobility decrease; in average, internal mobility decreases from $10 \%$ among employees aged under 30 to $3 \%$ among employees aged over 50. The larger a settlement is, the higher probability of internal mobility is. The larger a company is, the higher its internal mobility rates are. There are higher chances of vertical mobility in companies owned by foreigners. Employees who have subordinates have more chances for internal mobility.

\section{REFERENCES}

[1] Gimpelson V., Kapeliushnikov R., Sharunina A. The Pathways We Choose: Intra- and Interfirm Transitions. The HSE Economic Journal 2(20)-. p. 201-242. (2016)

[2] Frederiksen, A., Halliday T., Koch A. K. Within-and cross-firm mobility and earnings growth .ILR Review. 216. Vol. 69. №. 2. p. 320-353.(2016)

[3] Javdani, M., McGee A. Moving Up or Falling Behind? Gender, Promotions, and Wages in Canada. Institute for the Study of Labor (IZA), №. 9380.(2015)

[4] Dohmen, T. J., Kriechel B., Pfann G. A. Monkey bars and ladders: The importance of lateral and vertical job mobility in internal labor market careers // Journal of Population Economics. Vol. 17. №. 2. p. $193-$ 228(2004)

[5] Bidwell, M. Paying more to get less: The effects of external hiring versus internal mobility // Administrative Science Quarterly. Vol. 56. №. 3. p. 369-407. (2011)

[6] Cassidy, H., DeVaro J., Kauhanen A. Promotion signaling, gender, and turnover: New theory and evidence // Journal of Economic Behavior \& Organization. Vol. 126. p. 140-166.(2016)

[7] Ferreira, P. The determinants of promotions and firm separations. ISER Working Paper Series. 2009. №. 11. p. 40

[8] Nesterova Darya V., Maltseva Inna O. Intrafirm labor Mobility: Career and Wages: Working paper WP15/2009/10. - Moscow: State University - Higher School of Economics, 2009. - 52 p. (in Russian) 
[9] Maltseva I.O\&Nesterova D.V. WITHIN-FIRM GENDER SEGREGATION: CAUSES . Proceedings of Voronezh state University№. 1. - p. 244-255.(2011)

[10] Solntsev, Sergey A. Top-managers' mobility in Russia: what has changed during the crisis in 2008?: Working paper WP15/2012/01; National Research University Higher School of Economics.- Moscow : Publishing House of the Higher School of Economics, 26 p. (in Russian).(2012)

[11] Magnus Ya.R., Katyshev P.K., Peresetsky A.A. Econometrics. Initial course: Textbook. - 6th ed., Pererab. and add. - M .: Delo, 2004. - p. 333

[12] Gimpelson V. Ye. And others. Choosing a profession: what did you learn and where did you find useful? // Economic Journal of the Higher Schoo of Economics. - 2009. - V. 13. - №. 2. - c. 172-216
[13] Fedorova E.P. and Utaralieva R.T. Intercompany Mobility in the Russian Labor Market// Baikal Research Journal . V. 9, № 3.(2017)

[14] Author, F., Author, S.: Title of a proceedings paper. In: Editor, F., Editor, S. (eds.) CONFERENCE 2016, LNCS, vol. 9999, pp. 1-13. Springer, Heidelberg (2016).

[15] Author, F., Author, S., Author, T.: Book title. 2nd edn. Publisher, Location (1999).

[16] Author, F.: Contribution title. In: 9th International Proceedings on Proceedings, pp. 1-2. Publisher, Location (2010).

[17] LNCS Homepage, http://www.springer.com/lncs, last accessed 2016/11/21. 